\title{
Experimental and analytical investigations of friction at lubricant bearings in passive suspension systems
}

\author{
Ali I. H. Al-Zughaibi $\mathbb{D}$
}

Received: 11 July 2017 / Accepted: 11 June 2018 / Published online: 22 June 2018

(C) The Author(s) 2018

\begin{abstract}
Friction is a very complex phenomenon, arising from the contact of surfaces. In many engineering applications, the success of models in predicting experimental results remains strongly sensitive to the friction model. In practice, it is not possible to determine an exact friction model; however, based on observation results and dynamic systems analysis, a recently proposed model of nonlinear friction at linear supported lubricant bearings is investigated. This model involved static friction, stiction region, and dynamic friction, which is consisted of transition, Stribeck effect, Coulomb and viscous frictions. On the other hand, this model is applied in the passive suspension system. Accordingly, a new quarter-car passive suspension model with the implementation of friction force is considered. Also, a vital experimental and simulation aspect is the generation of system input. Therefore, a nonlinear hydraulic actuator used, modelling this actuator including the dynamic of servovalve derived by the proportional-integral (PI) controller, is prepared. This study is validated experimentally, with simulation achieving $\mathrm{C}++$ compiler. Consequently, a good agreement between the experimental and simulation results is obtained, i.e., the nonlinear friction, passive suspension system and nonlinear hydraulic actuator models are entirely accurate and useful. The sug-
\end{abstract}

A. I. H. Al-Zughaibi ( $ه)$

Cardiff University School of Engineering Cardiff, Cardiff, United Kingdom

e-mail: Al-ZughaibiAI@cardiff.ac.uk gested PI controller successfully derived the hydraulic actuator to validate the control scheme.

Keywords Nonlinear friction Passive suspension . A nonlinear hydraulic actuator - Dynamic servovalve . PI control · Steady state

\section{List of symbols}

$A_{1 \mathrm{r}} \quad$ Actuator cross-sectional area for side1 $=$ $1.96 \mathrm{e}-3\left(\mathrm{~m}^{2}\right)$

$A_{2 \mathrm{r}} \quad$ Actuator cross-sectional area for side $2=$ $0.94 \mathrm{e}-3\left(\mathrm{~m}^{2}\right)$

A/D Converter analog to digital

$b_{\mathrm{d}} \quad$ Viscous damping $=260\left(\mathrm{~N} / \mathrm{m} \mathrm{s}^{-1}\right)$

$b_{\mathrm{t}} \quad$ Tyre damping $=3886\left(\mathrm{~N} / \mathrm{m} \mathrm{s}^{-1}\right)$

$B_{\mathrm{vr}} \quad$ Actuator viscous damping $=500$ $\left(\mathrm{N} / \mathrm{m} \mathrm{s}^{-1}\right)$

$C_{\mathrm{e}} \quad$ Tracking parameter

D Viscous coefficient $(\mathrm{N} / \mathrm{m} / \mathrm{s})$

D/A Converter digital to analog

$e 1 \quad$ Curvature degree

$g \quad$ Gravitational constant $\left(\mathrm{m} / \mathrm{s}^{2}\right)$

$k_{\mathrm{t}} \quad$ Tyre stiffness $=9.2 \mathrm{e} 5(\mathrm{~N} / \mathrm{m})$

$k_{\mathrm{S}} \quad$ Spring stiffness $=2.89 \mathrm{e} 4(\mathrm{~N} / \mathrm{m})$

$K_{\mathrm{i}} \quad$ Integral gain

$K_{\mathrm{p}} \quad$ Proportional gain

$K_{\text {fr }} \quad$ Servovalve flow constant $=0.99 \mathrm{e}-4$ $\left(\mathrm{m}^{3} \mathrm{~s}^{-1} / \mathrm{N}^{1 / 2}\right)$ 
$L_{\mathrm{d}} \quad$ Free length of viscous damping $=0.342$

(m)

$M_{\mathrm{b}} \quad$ Body mass $=240(\mathrm{~kg})$

$M_{\mathrm{r}} \quad$ Tyre mass $=5(\mathrm{~kg})$

$M_{\mathrm{T}} \quad$ Total mass $=285(\mathrm{~kg})$

$M_{\mathrm{W}} \quad$ Wheel mass $=40(\mathrm{~kg})$

$P_{1 \mathrm{r}}, \mathrm{P}_{2 \mathrm{r}} \quad$ Pressures $\left(\mathrm{N} / \mathrm{m}^{2}\right)$

$P_{\text {sr }} \quad$ Supply pressure $=200 \mathrm{e} 5\left(\mathrm{~N} / \mathrm{m}^{2}\right)$

Q1r, Q2r Flow rates $\left(\mathrm{m}^{3} / \mathrm{s}\right)$

$R_{\text {ir }} \quad$ Internal leakage resistance $=2.45$

$\mathrm{e} 11\left(\mathrm{~N} / \mathrm{m}^{5} / \mathrm{s}\right)$

$u_{\mathrm{r}} \quad$ Servovalve control

$V_{1 \mathrm{r} 0} \quad$ Actuator volume for side $1=80 \mathrm{e}-6\left(\mathrm{~m}^{3}\right)$

$V_{2 \mathrm{r} 0} \quad$ Actuator volume for side2 $=167 \mathrm{e}-6\left(\mathrm{~m}^{3}\right)$

$V_{1 \mathrm{r}} \quad$ Dynamic actuator volume side $1\left(\mathrm{~m}^{3}\right)$

$V_{2 \mathrm{r}} \quad$ Dynamic actuator volume side $2\left(\mathrm{~m}^{3}\right)$

$x_{\mathrm{sr}} \quad$ Spool movement (m)

$\beta_{r} \quad$ Effective bulk modulus $=1.43 \mathrm{e} 9\left(\mathrm{~N} / \mathrm{m}^{2}\right)$

$\mu \quad$ Friction coefficient

$\tau_{\mathrm{r}} \quad$ Time servovalve constant (s)

\section{Introduction}

Despite numerous invaluable employments of friction, e.g., in metalworking, movement of vehicles, driving transmission with the use of frictional elements, also walking or vibration of strings in musical instruments, still there are various negative aspects of friction in the form of noise, wear and unpredictable behaviour of multiple mechanisms. Usually, friction is not wanted, so a great deal has been done to reduce it by design or by control. Friction behaviour can be divided into two regimes: gross sliding and pre-sliding [1]. Awrejcewicz and Olejnik [2] presented an algorithm for numerical integration of the ordinary differential equations including discontinuous term describing friction. The introduced algorithm depended on the Henon method, which is used to locate and track the stick to slip and slip to stick transitions. This numerical technique further referred a way used to investigate and to estimate the validity of various approximations to frictional behaviour.

Al-Bender et al. [3] mentioned the spearheading work of Amontons, Coulomb and Euler attempted to clarify the friction concept regarding the mechanism of relative movement of irregular surfaces in contact with one another. They lacked a precise dynamic model. Therefore, the requirement for such a model is becom- ing urgent; accordingly, if the researchers were able to qualify and quantify this friction force dynamics, it would be a relatively more uncomplicated step to treating the dynamics of a whole system comprising the friction. Thus, our results are consistent with their findings; the investigation indicates a functional dependence upon a large variety of parameters, including sliding speed, acceleration, normal load and types of input. Most of the current model-based friction compensation schemes used classical friction models, such as Coulomb and viscous frictions. In requests with highprecision positioning and with little velocity tracking, the results are not always satisfactory. A superior description of the friction phenomena for small speeds and especially when crossing zero speed is necessary. Friction is an accepted phenomenon that is quite difficult to model, and it is not yet completely understood [4].

The identification approach was developed by [5], to extend the frequency-domain view to extract the multiple varying stiffnesses of the pre-sliding friction in the generalised Maxwell-slip model based on the frictional resonance, which was a frequency-domain reflection of the hysteretic nonlinear behaviour of the pre-sliding friction. Culbertson and Kuchenbecker [6] assessed their endeavours to render very sensible virtual surfaces by growing their past work in surface rendering to incorporate surface friction and tapping transients, in a different way about what this study be conducted. The models include three components: surface friction, tapping transients and texture vibrations.

Kudish [7] considered frictional stresses cause the tangential displacements of contact surfaces and the estimates of the lubrication film thickness and frictional stresses can be significantly diminished and carried into a reasonable range compared to the observation measured. Also, the researcher proposed a stable numerical procedure for actual modelling surface sliding velocity and the rest of the elastohydrodynamically lubricated contact parameters.

Pilipchuk et al. [8] thought that the brake squeal phenomenon was generally observed at the last phase of braking process causing the decelerating sliding, which was very slow as compared to the temporal scales of friction-induced vibrations related with elastic modes of braking systems. Considering the transitional impacts was vital to comprehend physical conditions of the beginning of squeal occurrence, including conceivable mechanisms of excitation of acoustical strategies. 
The applications covered water-lubricated shipboard bearings [9-12]. These studies were dominated by experimental tests of section models that emulated the actual bearing dynamics. Different dynamic characteristics were predicted from the numerical simulation of the equations of motion and were exhibited by a bifurcation diagram revealing different regimes. These regimes include modulated response signals characterised by two frequency responses, intermittent on-off motion representing the incipient of squeal behaviour and limit cycles accompanied by highfrequency components. The occurrence of each regime mainly depends on the value of the slope of the frictionspeed curve.

The role of nonlinearity due to the friction-speed curve as well as the time variation of the friction coefficient has been considered in many other studies. The time variation of the static friction in relation to stickslip vibration has been studied experimentally [1317]. These studies revealed two factors responsible for increasing the value of the static friction coefficient, with time. These are the creep rate of compression of the asperities, increasing in the junction areas, and the shear strength of the junctions due to the existence of the cold-welding effect.

A state and maximum friction coefficient estimation using the joint unscented Kalman filter was presented by [18], and they considered a highly nonlinear vehicle model representing longitudinal and lateral dynamics.

From an application point of view, a quarter-car model can successfully be used to analyse the suspension system responses to road inputs. The system reactions with different road excitations and the model were established by [19].

In the majority of the prior research, [20-24], a quarter-car is modelled in which the spring and viscous dampers are moved vertically, with the inclination effects being ignored. Conversely, these are most inclined. On the other hand, simulation of the passive suspension test rig used the conventional model that is depicted in Fig. 1a and presented as a schematic diagram in Fig. 1b confronted an issue that there is a significant difference between the body movements for experimental and simulation results. Consequently, to overcome this issue, the suspension model should be modified by taking into account the actual inclined position of the spring and damper units and the reality of sliding the body on the lubri- cant bearings. Therefore, the friction force effects at supported body bearings that will play a pivotal role in reducing body oscillation should be considered.

In the current study, it was found that the friction helps to remove the oscillation from the body displacement as damping contributions. Accordingly, implementation of the friction with the quarter-car suspension model is a novel contribution.

This paper is organised as follows: Sect. 2 states the dynamics of the nonlinear hydraulic actuator including servovalve equation, Sect. 3 displays the hypothesis question why friction should be considered, with the clarified observations that motivate being considered. Section 4 demonstrates the promising nonlinear friction model in detail, while the new passive suspension system model is established in Sect. 5; the experimental and simulation results are validated and discussed in Sect. 6. Finally, Sect. 7 indicates the key outcomes and the potential track to grow the current results and suggestions for future work.

\section{Road simulator model}

The test rig can create a step and sine wave system inputs. Step input was used; this was potential because it is critical and helpful to show the system response. Also, regarding the construction of test rig, it was impossible to provide the step input directly since the piston actuator should be firstly moved from ground to midpoint and then be provided with the step input. Accordingly, the system input was designed to be mixed between the ramp and step inputs; however, there is a drawback with this input that was so severe; therefore, it was passed through a low-pass first-order filter to be more convenient with test rig to avoid damage. Therefore, this system is dynamically related, and the dynamic behaviour of the road simulator system becomes one of the essential factors in this study and should be investigated.

\subsection{Mathematical system input model}

Considering Fig. 1b, road simulator schematic diagram and the conventional modelling $[25,26]$, the spool valve 
Fig. 1 a Photograph of the test rig. b Schematic diagram of test rig and road simulator

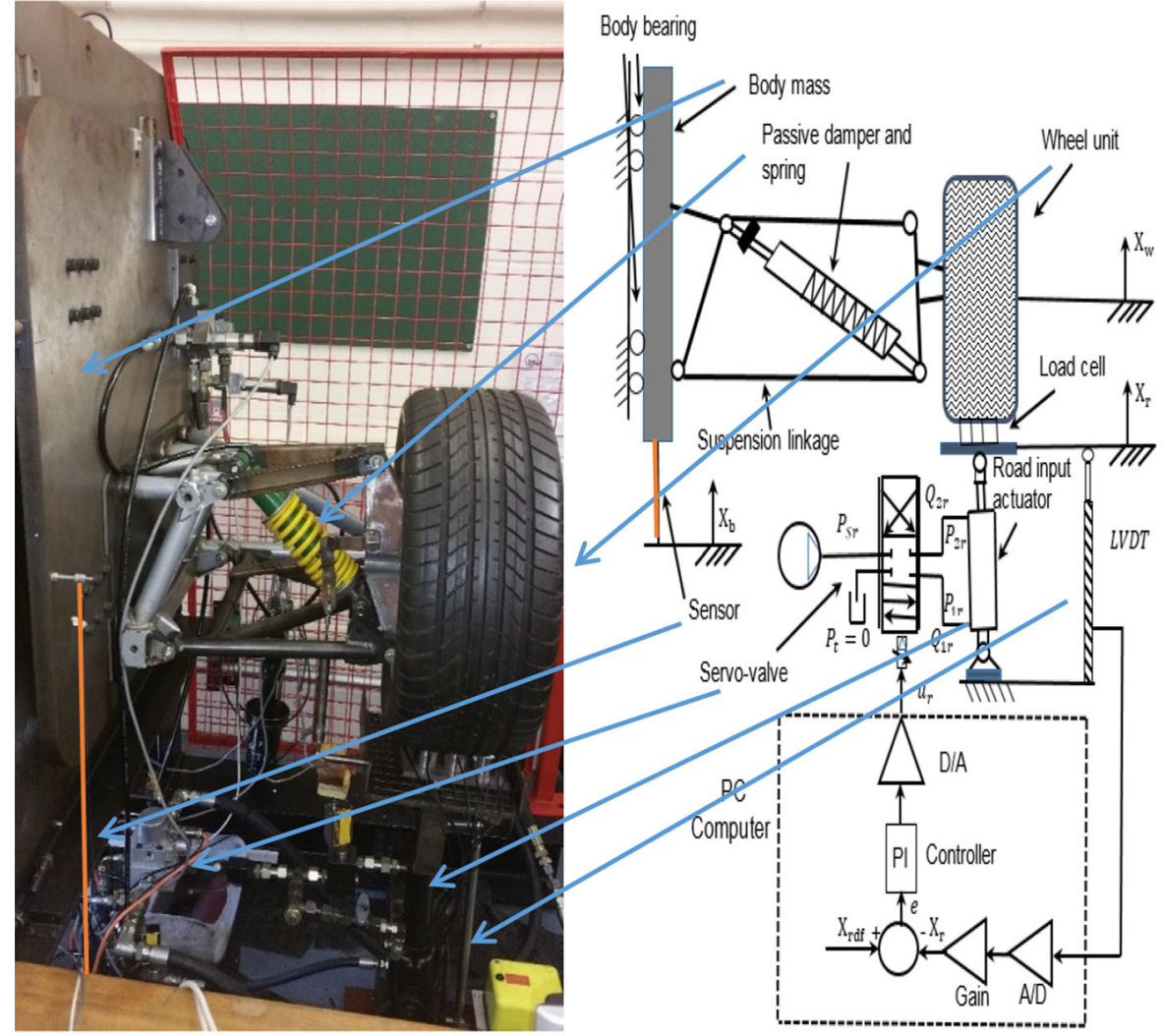

(b) displacement $x_{\mathrm{sr}}$ is related to the voltage input $u_{\mathrm{r}}$ by a first-order system is given by:

$$
\dot{x}_{\mathrm{sr}}=\frac{1}{\tau_{\mathrm{r}}}\left(u_{\mathrm{r}}-x_{\mathrm{sr}}\right)
$$

Therefore, depending on the direction of servovalve spool movement, there are two cases:

Casel for $x_{\mathrm{sr}} \geq 0$ when extending

The flow rates equations are:

$$
\begin{aligned}
& Q_{1 \mathrm{r}}=K_{\mathrm{fr}} x_{\mathrm{sr}} \sqrt{\left|P_{\mathrm{sr}}-P_{1 \mathrm{r}}\right|} \operatorname{sign}\left(P_{\mathrm{sr}}-P_{1 \mathrm{r}}\right) \\
& Q_{2 \mathrm{r}}=K_{\mathrm{fr}} x_{\mathrm{sr}} \sqrt{\left|P_{2 \mathrm{r}}\right|} \operatorname{sign}\left(P_{2 \mathrm{r}}\right)
\end{aligned}
$$

Case 2 for $x_{\mathrm{sr}}<0$ when retracting

The flow rates equations are:

$$
\begin{aligned}
& Q_{2 \mathrm{r}}=K_{\mathrm{fr}} x_{\mathrm{sr}} \sqrt{\left|P_{\mathrm{sr}}-P_{2 \mathrm{r}}\right|} \operatorname{sign}\left(P_{\mathrm{sr}}-P_{2 \mathrm{r}}\right) \\
& Q_{1 \mathrm{r}}=K_{\mathrm{fr}} x_{\mathrm{sr}} \sqrt{\left|P_{1 \mathrm{r}}\right|} \operatorname{sign}\left(P_{1 \mathrm{r}}\right)
\end{aligned}
$$

The flow rate equations, including compressibility and cross-line leakage effects for both sides, may be written.

$$
\begin{aligned}
& \frac{V_{1 \mathrm{r}}}{\beta_{\mathrm{r}}} \dot{P}_{1 \mathrm{r}}=Q_{1 \mathrm{r}}-A_{1 \mathrm{r}} \dot{X}_{\mathrm{r}}-\frac{\left(P_{1 \mathrm{r}}-P_{2 \mathrm{r}}\right)}{R_{\mathrm{ir}}} \\
& \frac{V_{2 \mathrm{r}}}{\beta_{\mathrm{r}}} \dot{P}_{2 \mathrm{r}}=A_{2 \mathrm{r}} \dot{X}_{\mathrm{r}}+\frac{\left(P_{1 \mathrm{r}}-P_{2 \mathrm{r}}\right)}{R_{\mathrm{ir}}}-Q_{2 \mathrm{r}}
\end{aligned}
$$

Also, the 2nd Newton's law for mass tyre is,

$$
\begin{aligned}
\ddot{X}_{\mathrm{r}} M_{\mathrm{r}}= & P_{1 \mathrm{r}} A_{1 \mathrm{r}}-P_{2 \mathrm{r}} A_{2 \mathrm{r}}-B_{\mathrm{vr}} \dot{X}_{\mathrm{r}}-k_{\mathrm{t}}\left(X_{\mathrm{r}}-X_{\mathrm{w}}\right) \\
& -b_{\mathrm{t}}\left(\dot{X}_{\mathrm{r}}-\dot{X}_{\mathrm{w}}\right)-M_{\mathrm{T}} g
\end{aligned}
$$

A small voltage is used to control the servovalve. The measured road input from the test rig (LVDT's sensor) as feedback is used through the data acquisition to PC card to convert from analog to digital to be adapted to use for design a controller. This voltage is passed through an amplifier, which provides the condition power to alter the valve's position to control the flow rates. The main drawback of state feedback law 
is that it cannot remove the steady-state errors due to hydraulic leakages and constant disturbances or reference input commands. Consequently, it is necessary to consider the controller structure that contains an integral action.

The suggested PI controller is:

$$
\begin{aligned}
& u_{\mathrm{r}}(t)=K_{\mathrm{p}} \operatorname{er}(t)+K_{\mathrm{i}} \int_{0}^{\mathrm{t}} \operatorname{er}(t) \mathrm{d} t \\
& \operatorname{er}(t)=X_{\mathrm{rdf}}(t)-X_{\mathrm{r}}(t)
\end{aligned}
$$

Note: For more detail, see "Appendix."

\section{Why considering friction within this study?}

In our test rig, a quarter-car, to achieve the primary target of this test rig and the requirements of design, the designer had to force the mass body movements in a vertical line. Therefore, a $240-\mathrm{kg}$ plate, used to represent a quarter-car body, is organised to move vertically via two linear supporting lubricant bearings. Two rails (THK type HSR 35CA), $1000 \mathrm{~mm}$ long and parallel to each other, are used with each linear bearing. A double wishbone suspension linkage was chosen because it preserves the geometry of a wheel in an upright position independent of the suspension type used. They connect the wheel hub to the chassis, which is attached to the car body. However, the inclined position of spring and damper should be taken account; this design helps to create a normal force at the body bearings with regard to the system inputs as shown by the free body diagram of test rig latter. This force is responsible for generating Coulomb friction force. Also, the mass body has been sliding on these lubricant bearings, i.e., this undoubtedly produces viscous friction. Therefore, it is crucial to investigate this friction qualified to their critical effects.
From a validation point of view, the experimental work was first done; simulation of these preliminary tests through using a conventional quarter-car passive suspension model faced an issue; it was found that there is a significant difference in the body movements between them. Consequently, the consideration of friction force becomes urgent; however, there are two clear indicators with experiential results assisted to notice the friction effects as follows:

\subsection{The dynamic indicator}

From mathematical model simulation results, it was found that there is considerable fluctuations in the body movements that is what generally is supposed from a quarter-car conventional suspension model. Watton [17], for the same test rig, mentioned that there was an oscillation for the car body travels in both experimental and simulation results. Although the body moved with clear oscillation in the simulation results, it interestingly did not happen in the experimental results as shown in Fig. 2, in contrast to what Watton declared. However, Fig. 2 demonstrates the measured and simulation results for conventional system model of the wheel and body displacements. It is precisely seen that the body travels supporting the wheel displacement in both experimental and simulation results with apparent fluctuation in simulation rather than the experiment; this disagreement is called the dynamic friction indicator.

\subsection{The static inductor}

The observation test demonstrated the suspension movements $\left(X_{\mathrm{w}}-X_{\mathrm{b}}\right)$ as shown in Fig. 3, which are directly recorded from the test rig LVTDs transducers readings; these results with significant noises qualified
Fig. 2 Experimental and Simulation results of $X_{\mathrm{w}}$ and $X_{\mathrm{b}}(\mathrm{m})$
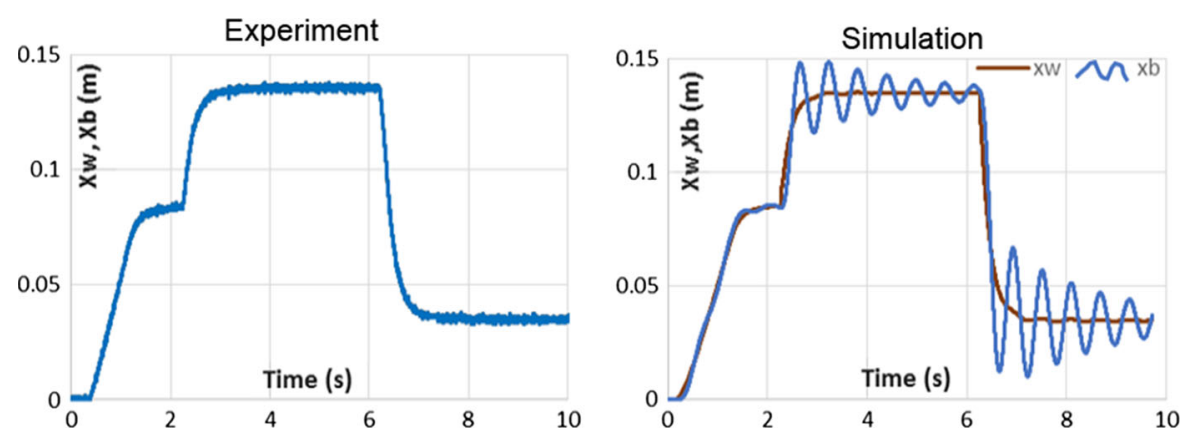
Fig. 3 Experimental results of the difference displacements between $X_{\mathrm{W}}$ and $X_{\mathrm{b}}(\mathrm{m})$

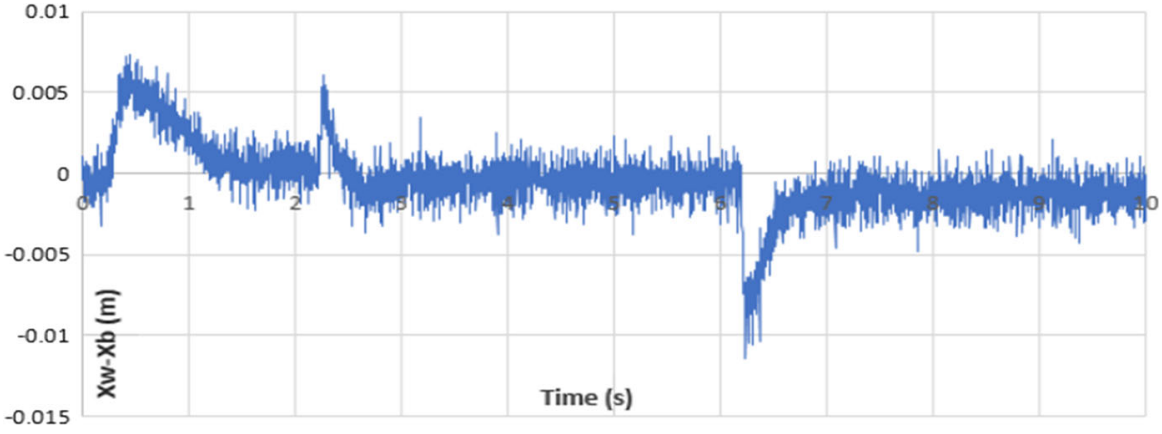

to sensor's characteristics. It is clearly seen that there is a zero difference between $X_{\mathrm{w}}$ and $X_{\mathrm{b}}$ in the starting or a short period and the beginning of test time; this could be because of data acquisition delay. Subsequently, the differences between them gradually increased, while the wheel starts to move up the body was stuck $\left(X_{\mathrm{b}}=0.0\right)$, until reaching the maximum. From that point forward, the results input force cope the stiction friction allowing the body to start moving. Therefore, the difference between them slowly reduced until reaching zero or close to zero at steady state (SS); the resting behaviour is following the system input force through two stages in positive and negative directions. This observation is named by the static friction indicator.

\section{How to account the normal bearings force}

Figure 4 shows the free body diagram of the test rig; the force acts as an internal force in the tangential direction of the contacting surfaces; this force obeys a constitutive equation such as Coulomb's law and operates in a direction opposite to the relative velocity. Therefore, this force should be identified.

The normal force that acts at the body lubricant bearings is:

$F_{\mathrm{nb}}=\left[\frac{\left(k_{\mathrm{s}}\left(X_{\mathrm{w}}-X_{\mathrm{b}}\right)+b_{\mathrm{d}}\left(\dot{X}_{\mathrm{w}}-\dot{\mathrm{X}}_{\mathrm{b}}\right)\right.}{\tan (\theta \mp \Delta \theta)}\right]$

Also, the construction linkage angle is dynamically changed by $\mp \Delta \theta$; from the geometric analysis, it is found that:

$\Delta \theta=\sin ^{-1}\left[\frac{\left(X_{\mathrm{w}}-X_{\mathrm{b}}\right) \sin (\theta)}{L_{\mathrm{d}}-\left(X_{\mathrm{w}}-X_{\mathrm{b}}\right) \sin (\theta)}\right]$

Note: For more detail, see "Appendix."

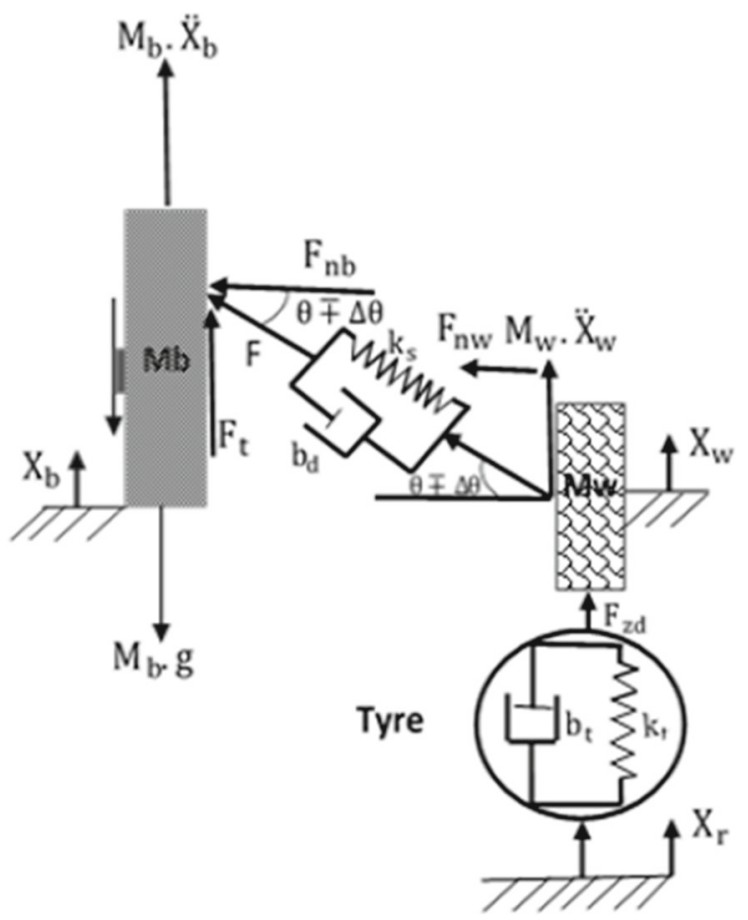

Fig. 4 Free body diagram of test rig

\section{Nonlinear frictions model}

To achieve the high level of performance, frictional effects have to be addressed by considering accurate frictions model, such that the resulting model would simulate all observed types of friction behaviour faithfully.

Based on the experimental measurements and the dynamic system analysis, a promising friction model is developed. This model includes a static friction effect (stiction region), a linear term (viscous friction), a nonlinear term (Coulomb friction) and a further component at low velocities (Stribeck effect). During acceleration, 
the magnitude of the frictional force at just after zero speed is dipped due to Stribeck effects according to the value and direction of the body velocity given as follows:

$$
F_{\text {fric }}= \begin{cases}k_{\mathrm{s}}\left(X_{\mathrm{w}}-X_{\mathrm{b}}\right)+b_{\mathrm{d}}\left(\dot{X}_{\mathrm{w}}-\dot{X}_{\mathrm{b}}\right) & \dot{X}_{\mathrm{b}}=0.0 \\ C_{\mathrm{e}} \mathrm{e}^{\left(\left|\dot{X}_{\mathrm{b}}\right| / e 1\right)}+\left[\frac{\mu\left(k_{\mathrm{s}}\left(X_{\mathrm{w}}-X_{\mathrm{b}}\right)+b_{\mathrm{d}}\left(\dot{X}_{\mathrm{w}}-\dot{X}_{\mathrm{b}}\right)\right)}{\tan (\theta \mp \Delta \theta)}\right]+\mathrm{D} \dot{X}_{\mathrm{b}} & \dot{X}_{\mathrm{b}}>0.0 \\ -C_{\mathrm{e}} \mathrm{e}^{\left(\left|\dot{X}_{\mathrm{b}}\right| / e 1\right)}+\left[\frac{\mu\left(k_{\mathrm{s}}\left(X_{\mathrm{w}}-X_{\mathrm{b}}\right)+b_{\mathrm{d}}\left(\dot{X}_{\mathrm{w}}-\dot{X}_{\mathrm{b}}\right)\right)}{\tan (\theta \mp \Delta \theta}\right]+\mathrm{D} \dot{X}_{\mathrm{b}} \dot{X}_{\mathrm{b}}<0.0\end{cases}
$$

the influence of the friction transfer from direct contact between the bearings and the body into mixed lubrication mode at low velocity; this is possibly due to lubricant film behaviours.

This model, which has now become well established, has been able to give a more satisfactory explanation for the observation of removing body dynamics fluctuation. It will be attempted heuristically to "fit" a dynamic model to experimentally observed results. The resulting model is not only valid for our test rig behaviour, which can accurately provide a physical explanation but is also reasonably suitable for most general similar cases.

The model simulates the symmetric hysteresis loops observed at the body bearings undergoing forcing inputs. The influence of hysteresis phenomena on the dynamic behaviour of machine elements with moving parts is not thoroughly examined in the literature yet. In other fields of engineering, where hysteretic phenomena manifest themselves, more research has been conducted. In reference [27], for example, adaptive modelling techniques were proposed for dynamic systems with hysteretic elements. The methods were general, but no insight into the influence of the hysteresis on the dynamics was given, and no experimental verification was provided.

In this study, the formative friction model despite its extreme simplicity can simulate all experimentally perceived properties and facets of low-velocity friction force dynamics (that we are aware of). According to the test rig construction and the system input type, which is history travel, it is found three circumstances depending on whether the body velocity is accelerating or decelerating.

\subsection{Mathematical friction model}

The mathematical expression for the new friction model consists of three different sectors depending on where $F_{\text {fric }}$ is the total friction force in $(\mathrm{N})$.

In another word, Eq. (13) shows the friction model, which includes two main parts: static and dynamic frictions. The former is solely dependent on the velocity because the body velocity should be close zero or just cross zero often, whereas the latter is with two expressions dependent on the body velocity direction. Besides this friction model, the physics SS is investigated.

\subsubsection{Static friction model}

Since the force of friction at zero velocity can take any value between $+\mathrm{Fc}$ and $-\mathrm{Fc}$, the mathematical treatment is belonging to the problems of differential inclusion and differential equations with non-smooth right-hand side [28]. In the current study, at the beginning of test time, the wheel started to move according to the system input, whereas the body remained motionless $\left(X_{\mathrm{b}}=0.0\right)$; this is undoubtedly resulting in the stiction region. Accordingly, this friction is sufficiently accurate to describe the static friction, which is accounted through the test rig forces balance in the vertical direction $\left(\sum F_{\mathrm{v}}=0.0\right)$ as follows:

The following conventional model represents a quarter race car body motion without friction [29]:

$M_{\mathrm{b}} \cdot \ddot{X}_{\mathrm{b}}=\left[k_{\mathrm{s}}\left(X_{\mathrm{w}}-X_{\mathrm{b}}\right)+b_{\mathrm{d}}\left(\dot{X}_{\mathrm{w}}-\dot{X}_{\mathrm{b}}\right)\right]$

where $X_{\mathrm{w}}, X_{\mathrm{b}}$ are the wheel and body movements (m), $\dot{X}, \dot{X}$ are the wheel and body velocities, respectively $(\mathrm{m} / \mathrm{s}), \ddot{X}$ is the body acceleration $\left(\mathrm{m} / \mathrm{s}^{2}\right)$.

This is a first time to implement the friction forces within the Newton's 2nd law for a quarter-car model. Therefore, the new dynamic equation of motion for the body becomes:

$$
M_{\mathrm{b}} \cdot \ddot{X}_{\mathrm{b}}=\left[k_{\mathrm{s}}\left(X_{\mathrm{w}}-X_{\mathrm{b}}\right)+b_{\mathrm{d}}\left(\dot{X}_{\mathrm{w}}-\dot{X}_{\mathrm{b}}\right)\right]-F_{\text {fric }}
$$


At the beginning and a short period of the test time, the body remained motionless $\left(X_{\mathrm{b}} \cong 0.0\right)$ and $\left(\ddot{X}_{\mathrm{b}} \cong\right.$ $0.0)$. Therefore, Eq. (15) becomes:

$$
0.0=\left[k_{\mathrm{s}}\left(X_{\mathrm{w}}-X_{\mathrm{b}}\right)+b_{\mathrm{d}}\left(\dot{X}_{\mathrm{w}}-\dot{X}_{\mathrm{b}}\right)\right]-F_{\text {fric }}
$$

Then,

$$
F_{\text {fricS }}=k_{\mathrm{s}}\left(X_{\mathrm{w}}-X_{\mathrm{b}}\right)+b_{\mathrm{d}}\left(\dot{X}_{\mathrm{w}}-\dot{X}_{\mathrm{b}}\right)
$$

where $F_{\text {fricS }}$ is the static friction, whose magnitude is equal to the relative displacement and relative velocity between the wheel and body times the stiffness spring and viscous damper coefficients, respectively, with direction depending on the next stage $\dot{X}_{b}$ direction. From the experimental work, for the step input (amplitude $=0.005 \mathrm{~m}$ ), it was found that the maximum static friction force position occurs at $\left(X_{\mathrm{w}}-X_{\mathrm{b}}\right) \leq$ $0.0069 \mathrm{~m}$ and $X_{\mathrm{b}} \cong 0.0$. When the system at the breakaway force and just starts to slide, the friction force reaches this maximum force.

\subsubsection{Dynamic friction model}

Previous studies (see, e.g., [30-32]) have shown that a friction model involving dynamics was necessary to describe the friction phenomena accurately. A dynamic model representing the spring-like behaviour during stiction was proposed by [33]. The Dahl model was essentially Coulomb friction with a lag in the change in friction force when the direction of motion was changed; the model does not include the Stribeck effect. An attempt to incorporate this into the Dahl model was made by [34] where the authors introduced a second-order Dahl model using linear space invariant descriptions. There are also other models for dynamic friction; Armstrong-Helouvry proposed a seven-parameter model in [30]; this model does not combine the different friction phenomena but is, in fact, one model for stiction and another for sliding friction. Another dynamic model suggested by [35] is not defined at zero velocity. Pilipchuk and Ibrahim [36] inspected the parametric excitation of a double pendulum model with one pendulum that could encounter the affect with rigid walls by using the Zhuravlev coordinate transformation.

However, in this paper, a promotion dynamic friction model is proposed. This model combines the following: The transition behaviour from stiction to slid regime includes the Stribeck effect, Coulomb friction according to the normal dynamic force acting at the body bearings with a suitable friction coefficient and the viscous friction depending on the body velocity with an appropriate viscous coefficient. This model involved arbitrary SS friction characteristics. The most significant outcomes of this model highlight the hysteresis behaviours of the friction according to history behaviours of the body's displacement and velocity.

Refer to the system (13); there are two forms for the dynamic friction qualified by the body velocity direction as follows:

For $\dot{X}_{\mathrm{b}}>0.0$ the dynamic friction form is:

$$
\begin{aligned}
& F_{\text {fric }} \\
& =\left\{C_{\mathrm{e}} \mathrm{e}^{\left(\left|\dot{X}_{\mathrm{b}}\right| / e 1\right)}+\left[\frac{\mu\left(k_{\mathrm{s}}\left(X_{\mathrm{w}}-X_{\mathrm{b}}\right)+b_{\mathrm{d}}\left(\dot{X}_{\mathrm{w}}-\dot{X}_{\mathrm{b}}\right)\right)}{\tan (\theta \mp \Delta \theta)}\right]\right. \\
& \left.\quad+D \dot{X}_{\mathrm{b}}\right\}
\end{aligned}
$$

Virtually, this friction consists of three parts: portion one is with the form:

$F_{\text {fric }}=\left\{C_{\mathrm{e}} \mathrm{e}^{\left(\left|\dot{X}_{\mathrm{b}}\right| / e 1\right)}\right\}$

where $F_{\text {fric }}$ is the transition friction, $C_{\mathrm{e}}$ is the attracting parameter and $e 1$ is the curvature degree. The transition friction has exponential behaviour; it totally agrees with the literature reviews for lubricant friction, which started from the maximum value at the stiction region and quickly dipped with just the body being started to move or its velocity being grown.

Whereas part two representing Coulomb friction, which is equal to the normal bearing force times the friction coefficient $(\mu)$ as shown:

$F_{\text {fricC }}=\left\{\frac{\mu\left(k_{\mathrm{s}}\left(X_{\mathrm{w}}-X_{\mathrm{b}}\right)+b_{\mathrm{d}}\left(\dot{X}_{\mathrm{w}}-\dot{X}_{\mathrm{b}}\right)\right)}{\tan (\theta \mp \Delta \theta)}\right\}$

where $F_{\text {fricC }}$ is Coulomb friction.

Finally, part three demonstrates the viscous friction according to the lubricant bearings and body contact, which is counted from the body velocity times a viscous coefficient (D), as follows:

$F_{\text {fricV }}=\left\{D \dot{X}_{\mathrm{b}}\right\}$

where $F_{\text {fric }}$ is the viscous friction. 
Fig. 5 Body movement $\left(X_{\mathrm{b}}\right)$ as function of time

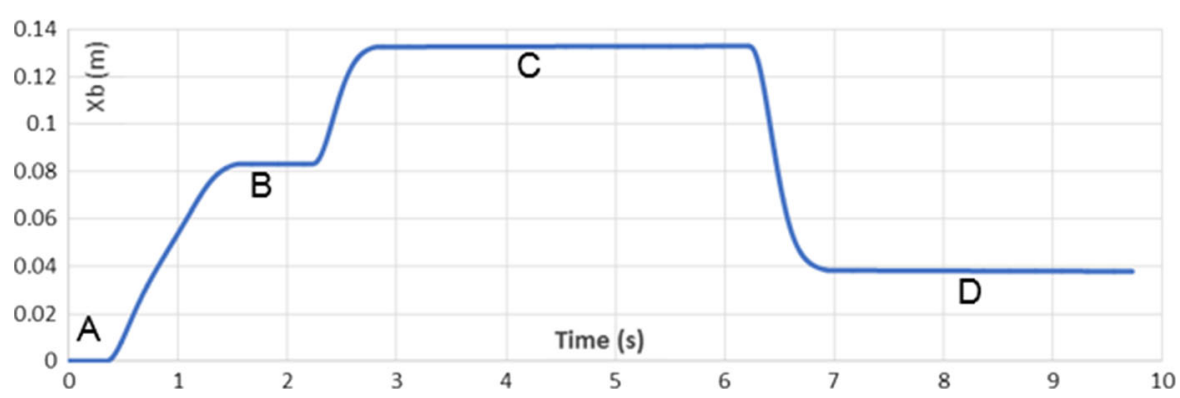

In respect of $\dot{X}_{\mathrm{b}}<$., the dynamic friction form is:

$$
\begin{aligned}
F_{\text {fric }}=\{ & -C_{\mathrm{e}} \mathrm{e}^{\left(\left|\dot{X}_{\mathrm{b}}\right| / e 1\right)} \\
& +\left[\frac{\mu\left(k_{\mathrm{s}}\left(X_{\mathrm{w}}-X_{\mathrm{b}}\right)+b_{\mathrm{d}}\left(\dot{X}_{\mathrm{w}}-\dot{X}_{\mathrm{b}}\right)\right)}{\tan (\theta \mp \Delta \theta)}\right] \\
& \left.+D \dot{X}_{\mathrm{b}}\right\}
\end{aligned}
$$

Equation (22) is quite similar to (18) with adding a negative sign for the transition friction term, because these values described the friction in the opposite direction relative to the velocity direction, i.e., negative frictions region.

\subsubsection{Steady-state friction}

It is vital to experience the friction behaviour within SS, by defining the threshold force, which is needed to cause across pre-sliding / sliding motion.

Figure 5 shows the body displacement behaviours as function of time; it is clearly seen that the moving body history has started to move from stiction region, $\left(X_{\mathrm{b}}=\right.$ 0.0 and $\dot{X}_{\mathrm{b}} \cong 0.0$ ); this is a first SS situation (A), then it reached the second SS stage (B), at the midpoint of the hydraulic actuator $\left(X_{\mathrm{b}}=0.085(\mathrm{~m})\right.$ and $\dot{X}_{\mathrm{b}} \cong$ $0.0(\mathrm{~m} / \mathrm{s}))$. Secondly, the body started to move from the second SS (B), and it reached the highest amplitude $\left(X_{\mathrm{b}}=0.135\right)$ and $\left(\dot{X}_{\mathrm{b}} \cong 0.0\right)$ at third SS stage $(\mathrm{C})$ according to the highest input force. Finally, it is started to move from the third SS stage $(\mathrm{C})$, and it reached the lowest value of amplitude input $\left(X_{\mathrm{b}}=0.035 \mathrm{~m}\right)$; the body travelled double distance compared with the second stage relative to the inputs, to end with reaching the four SS stage (D) at $\left(X_{\mathrm{b}}=0.035(\mathrm{~m})\right.$ and $\dot{X}_{\mathrm{b}} \cong$ $0.0)$.

At the stiction region and SS stages, $\ddot{X}_{\mathrm{b}}$ is equal to zero. Therefore, the friction in both cases is identified similar to the static friction as mentioned in (17). In general, the particular friction form in SS case is as follows:

$F_{\text {fricSS }}=\left[k_{\mathrm{s}}\left(X_{\mathrm{w}}-X_{\mathrm{b}}\right)+b_{\mathrm{d}}\left(\dot{X}_{\mathrm{w}}-\dot{X}_{\mathrm{b}}\right)\right]$

where $F_{\text {fricSs }}$ is SS friction.

\subsubsection{Simple friction model}

System (13) gives a general form for the nonlinear friction at the linear lubricant-supported body bearings. This model could be studied from the different point of view, i.e., it can be returned to two dominants parameters, the body velocity and the normal body force. The friction relative to the body velocity is named as damping friction, while Coulomb friction qualifies to the normal body force.

For simplicity, although the frictions model equation (13) covered most of the observation friction phenomena, still it could be used a simple form through overlooking Coulomb friction. Therefore, the new expression of friction without Coulomb is:

$$
F_{\text {fric }}= \begin{cases}k_{\mathrm{s}}\left(X_{\mathrm{w}}-X_{\mathrm{b}}\right)+b_{\mathrm{d}}\left(\dot{X}_{\mathrm{w}}-\dot{X}_{\mathrm{b}}\right) & \dot{X}_{\mathrm{b}}=0.0 \\ C_{\mathrm{e}} \mathrm{e}^{\left(\left|\dot{X}_{\mathrm{b}}\right| / e 1\right)}+D \dot{X}_{\mathrm{b}} & \dot{X}_{\mathrm{b}}>0.0 \\ -C_{\mathrm{e}} \mathrm{e}^{\left(\left|\dot{X}_{\mathrm{b}}\right| / e 1\right)}+\mathrm{D} \dot{X}_{\mathrm{b}} & \dot{X}_{\mathrm{b}}<0.0\end{cases}
$$

Equation (24) demonstrates the simple friction model, which has had the same three various sectors depending on $\dot{X}_{\mathrm{b}}$, values and directions. The interesting point, implementing this simple friction forms within the mathematical simulation model, also acquired a good agreement comparing with the experimental results regarding system response parameters. The urgent question is which one is more suitable for our case? The general friction model system (13) has been given 
more details to show their ability to highlight the hysteresis phenomena that should take place with this system input type, whereas the simple friction model (24) has lost to display hysteresis. In addition, a mathematical analysis is used to find which one is accurate, by using the residual mean square (RMS). Therefore, it used two measured parameters $X_{\mathrm{b}}$ and $X_{\mathrm{w}}-X_{\mathrm{b}}$ to show the accuracy of considering the general or simple friction form.

The RMS is accounted for the measured and mathematical simulation model results with and without Coulomb friction for the suspension movement, as follows:

$(\mathrm{RMS})_{\mathrm{c}}=\sqrt{\frac{1}{N} \sum\left(\left(X_{\mathrm{w}}-X_{\mathrm{b}}\right)_{\mathrm{m}}-\left(X_{\mathrm{w}}-X_{\mathrm{b}}\right)_{\mathrm{Sc}}\right)^{2}}$

And,

$(\mathrm{RMS})=\sqrt{\frac{1}{N} \sum\left(\left(X_{\mathrm{w}}-X_{\mathrm{b}}\right)_{\mathrm{m}}-\left(X_{\mathrm{w}}-X_{\mathrm{b}}\right)_{\mathrm{S}}\right)^{2}}$

where $(\mathrm{RMS})_{\mathrm{c}}$ and (RMS) are the RMS between measured and simulation values with and without considering Coulomb friction, respectively, $\left(X_{\mathrm{w}}-X_{\mathrm{b}}\right)_{\mathrm{m}}$ is the measured relative displacement. $\left(X_{\mathrm{w}}-X_{\mathrm{b}}\right)_{\mathrm{Sc}}$ and $\left(X_{\mathrm{w}}-X_{\mathrm{b}}\right)_{\mathrm{S}}$ are the simulation data with and without implementing Coulomb friction; $\mathrm{N}$ is the total number of sample. Table 1 demonstrates the RMS results.

\section{Passive mathematical model}

Consider the free body diagrams of both body and wheel masses as shown in Fig. 5. Consider quartercar model of a passively suspended vehicle, where $M_{\mathrm{b}}$ and $M_{\mathrm{w}}$ are the masses of the body and wheel, respectively. The road, wheel and car body displacements are $X_{\mathrm{r}}, X_{\mathrm{W}}$, and $X_{\mathrm{b}}$, respectively. The spring coefficients

Table 1 RMS results

\begin{tabular}{lll}
\hline Concerned variables & $(\mathrm{RMS})_{\mathrm{c}}$ & $(\mathrm{RMS})$ \\
\hline$\left(X_{\mathrm{w}}-X_{\mathrm{b}}\right)$ & 0.006362 & 0.006366 \\
$\left(X_{\mathrm{b}}\right)$ & 0.096267 & 0.096386 \\
\hline
\end{tabular}

for system and tyre are $k_{\mathrm{s}}$ and $k_{\mathrm{t}}$. The damper coefficient for the body and tyre are $b_{\mathrm{d}}$ and $b_{\mathrm{t}}$, respectively. $\theta$ is the construction angle. It should be noted that $X_{\mathrm{r}}, X_{\mathrm{W}}$ and $X_{\mathrm{b}}$ are mathematically referenced with an ideal ground, which does not exist in real world, but does exist in the laboratory environment. Vehicle suspensions are designed to minimise the car body acceleration $\ddot{X}_{\mathrm{b}}$ within the limitation of the suspension displacement $X_{\mathrm{w}}-X_{\mathrm{b}}$ and tyre deflection $X_{\mathrm{r}}-X_{\mathrm{w}}$.

Therefore, the new dynamic equation of motion for the body system becomes:

$M_{\mathrm{b}} \cdot \ddot{X}_{\mathrm{b}}=\left[k_{\mathrm{s}}\left(X_{\mathrm{w}}-X_{\mathrm{b}}\right)+b_{\mathrm{d}}\left(\dot{X}_{\mathrm{w}}-\dot{X}_{\mathrm{b}}\right)\right]-F_{\text {fric }}$

While the dynamic equation of motion for the wheel is:

$$
\begin{aligned}
M_{\mathrm{w}} \cdot \ddot{X}_{\mathrm{w}}= & -\left[k_{\mathrm{s}}\left(X_{\mathrm{w}}-X_{\mathrm{b}}\right)+b_{\mathrm{d}}\left(\dot{X}_{\mathrm{w}}-\dot{X}_{\mathrm{b}}\right)\right] \\
& +k_{\mathrm{t}}\left(X_{\mathrm{r}}-X_{\mathrm{w}}\right)+b_{\mathrm{t}}\left(\dot{X}_{\mathrm{r}}-\dot{X}_{\mathrm{w}}\right)
\end{aligned}
$$

where $\ddot{X}_{\mathrm{w}}$ is the wheel acceleration $\left(\mathrm{m} / \mathrm{s}^{2}\right)$.

\section{Experimental and simulation results}

In this study, comparison of system response results is done between the experimental works and mathematical simulation model results achieved through $\mathrm{C}++$ compiler environment. Experimental work and simulation are accomplished as a function of amendment into step input parameter; these results are gained by setting up the step input amplitude at $50 \mathrm{~mm}$, which is the distance between the midpoints to top-point of the actuator.

Figure 6 presents a comparison between the experiment and simulation for road simulator inputs; the original one $\left(X_{\mathrm{rd}}\right)$, mixed between the ramp and step input, is passed through a first-order filter to be more appropriate with the test rig to avoid damage and the measured input $X_{\mathrm{r}}$. It is clearly seen that these inputs are quite similar in both the experiment and simulation; this is vital in establishing a satisfactory comparison between them. Figure 7 demonstrates validation of the experimental wheel and body displacements by simulation results. It is evidently seen that there is a delay for body travels according to the wheel movements at the beginning of test time; this is undoubtedly caused by the static friction force, and in general, they travel following the road input showing the friction effects. 
Fig. 6 Comparison of step inputs $X_{\mathrm{rd}}, \quad X_{\mathrm{r}}(\mathrm{m})$

Fig. 7 Comparison of $X_{\mathrm{w}}$ and $X_{\mathrm{b}}(\mathrm{m})$

Fig. 8 Comparison between $\dot{X}_{\mathrm{w}}(\mathrm{m} / \mathrm{s})$ and $\dot{X}_{\mathrm{w}}$ (wheel velocity)
Experiment results
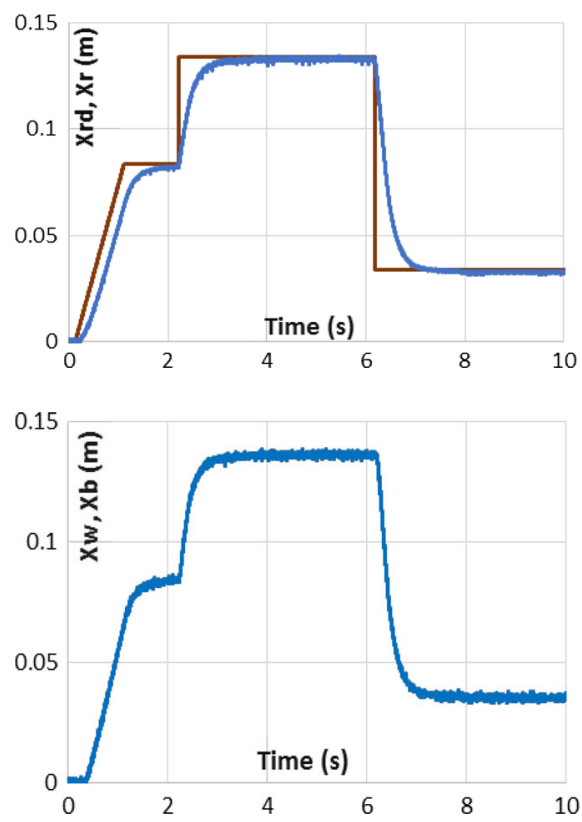

Simulation results
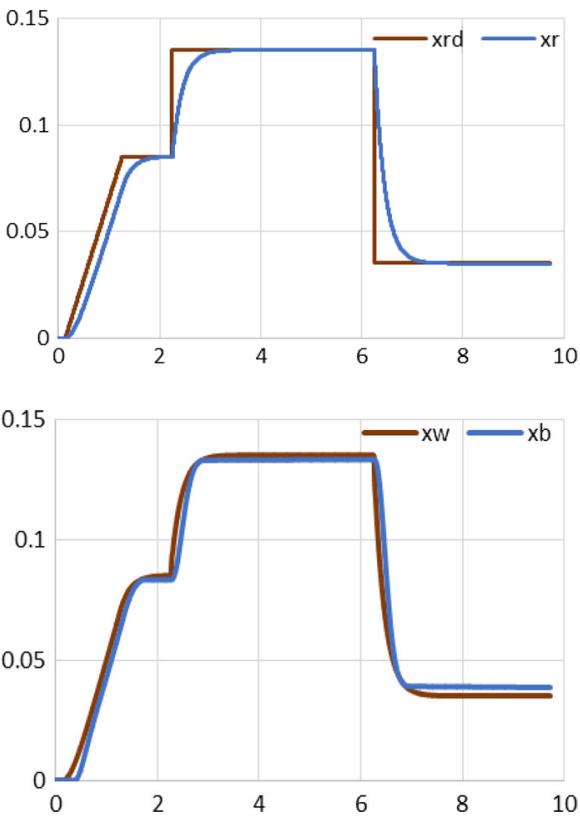

Simulation results

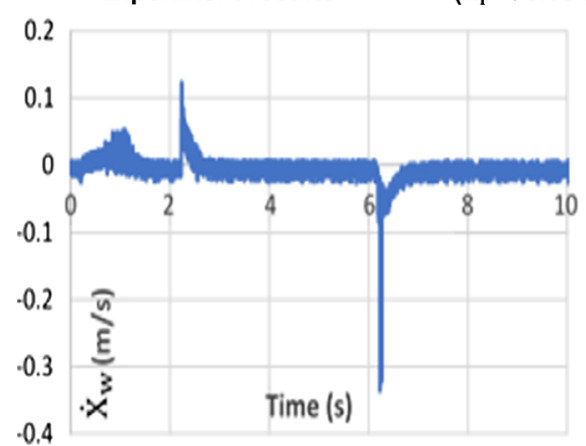

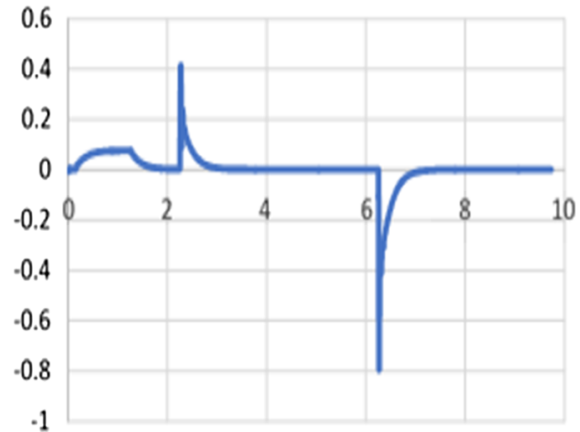

Figure 8 displays the measured wheel velocity and their simulation model result in a good agreement. Although observed a slight difference in values, the simulation values are higher than the experimental values; this usually occurs according to physical energy consumed. A substantial agreement for the body velocity for both experimental and simulation results are shown in Fig. 9; this is gained from considering the friction force. In general, the experiment results in extreme noises that could be relative to the sensitivity of sensors.

Figure 10 illustrates the suspension movements $\left(X_{\mathrm{w}}-X_{\mathrm{b}}\right)$ in $(\mathrm{m})$, for the experimental and simulator mathematical model results. It is essential to display this response in order to identify the allowance of working space or might be to find the weather condition of the test rig. In addition, this relative displacement has a direct close link to the real-world situation. It is clearly seen that at the beginning of test time, there is a significant difference between the wheel and body travels. That is confidently relative to the stiction region. Subsequently, the total input forces will be greater than threshold force, i.e., $\left(\dot{X}_{\mathrm{b}}>0.0\right)$ that leads to gradually decrease this difference until reaching zero or close to zero at the second SS stage while the resting behaviour according to system input with showing the friction effects. This information successfully helps to create a physical explanation for the observation friction phenomena.

However, Fig. 11 demonstrates the total nonlinear friction as a function of the body velocity. The test 
Fig. 9 Comparison between $\dot{X}_{\mathrm{b}}(\mathrm{m} / \mathrm{s})$ and $\dot{X}_{\mathrm{b}}$ (body velocity)
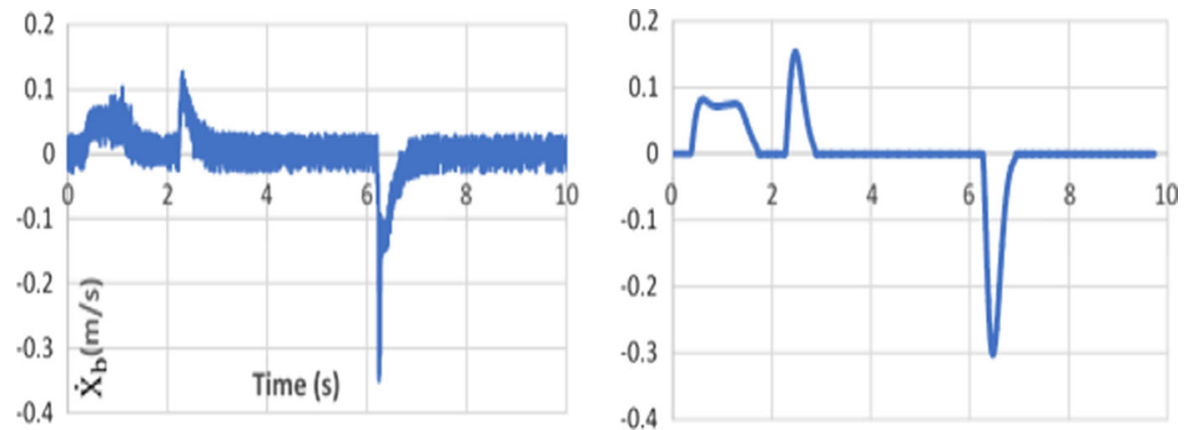

Fig. 10 Comparison of suspension movement $\left(X_{\mathrm{w}}-X_{\mathrm{b}}\right)(\mathrm{m})$

Fig. 11 General friction as function of the body velocity $(N)$
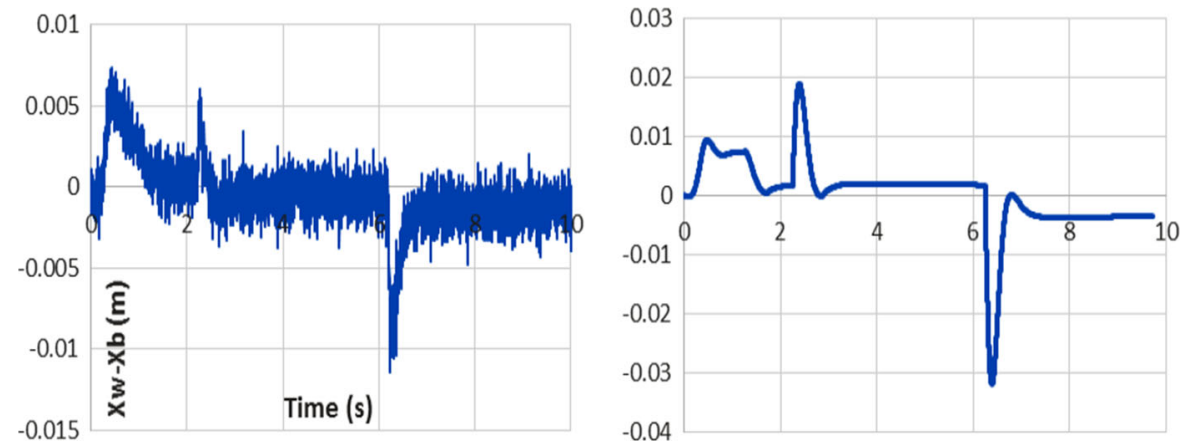

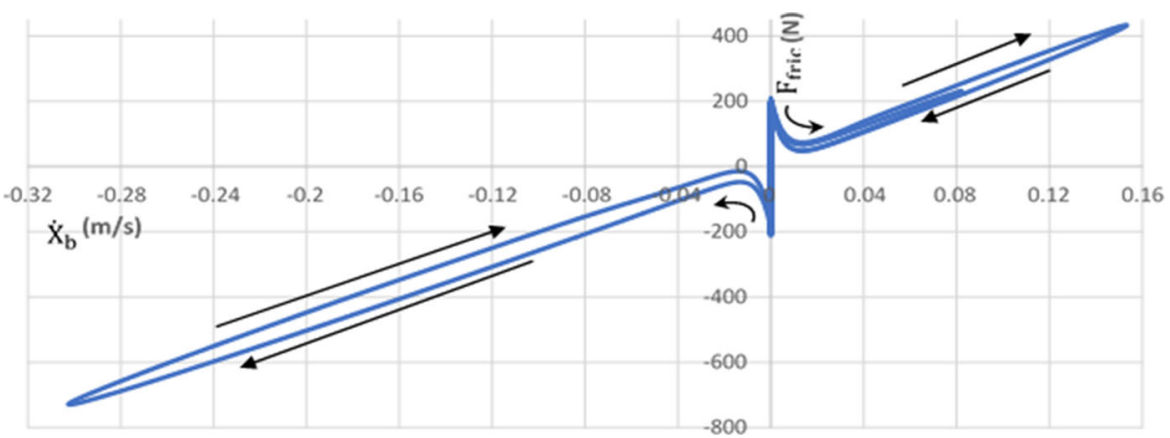

rig construction and the type of system input with history travel together help to generate the hysteresis friction behaviours. This influenced by the body velocity is accelerating or decelerating, the velocity values start from zero, and just after velocity reversals reach the highest and rebounded to zero or close to zero at SS stages. Therefore, it is clearly seen that at $\dot{X}_{\mathrm{b}}=0.0$, stiction area, the friction is equal to static friction, as shown in the system (18), depending on the next velocity direction. After that, at just across $\dot{X}_{\mathrm{b}}=0.0$, the friction directly dips qualifying to Stribeck effects; this could be because of the hydraulic layer behaviours and the contact changing from a direct dry to mixed hydraulic. $\dot{X}_{\mathrm{b}}>0.0$ helps the friction to generate two hysteresis loops in a positive direction, while $\dot{X}_{\mathrm{b}}<0.0$ acts to draw a hysteresis loop in the opposite direction with double values according to the input force.

Figure 12 shows the simple friction force overlooking Coulomb friction. It is evident that there are no hysteresis friction behaviours with losing the features of the two-cycle frictions in positive stages in comparing with general form, as mentioned in Sect. 5.1.4. This is undoubtedly evidence that implementation of the general friction model with considering Coulomb friction is quite suitable.

The association between the friction without considerable Coulomb friction, damping friction and Coulomb friction as a function of the body velocity is demon- 
Fig. 12 Damping friction (without Coulomb friction), as function of the body velocity $(N)$

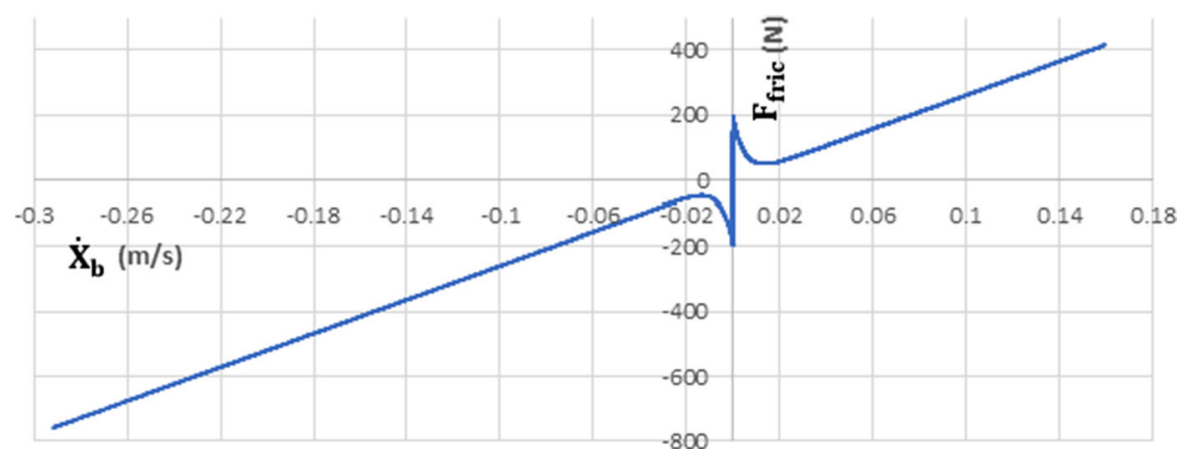

Fig. 13 Demonstration of damping and Coulomb friction as function of the body velocity $(N)$

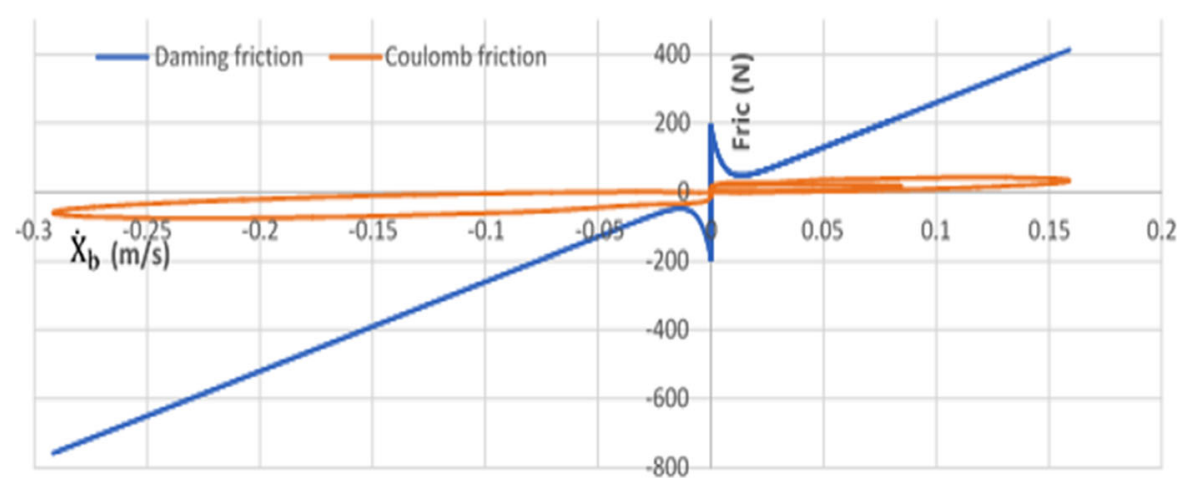

strated in Fig. 13. It is clearly seen that damping friction is dominant, but Coulomb friction has brought the hysteresis behaviour.

\section{Conclusion}

The nonlinear friction model is established according to the observation measurements and dynamic system analysis. Both simulation and experimental results showed consistent agreement between them, which consequently confirmed the feasibility of the new relay model for the passive suspension system, taking into account the actual configuration of the test rig system and the fact of lubrication slip body. This model subsequently considers the nonlinearity friction force that affects the supported body bearings and is entirely accurate and useful. The nonlinear friction model captured most of the friction behaviours that have been observed experimentally, such as stiction region, Stribeck effects, Coulomb and viscous frictions, which are individually responsible for causing the relatively significant difference between the wheel and body movement at the beginning of test time and so on. The general nonlinear friction model, with consideration of Coulomb friction, is more precise and quite suitable for our case in comparison with the simple friction model. Also, the nonlinear hydraulic actuator and the dynamic equation of servovalve models are moderately accurate and practical. The suggested PI controller successfully derived the hydraulic actuator to validate the control strategy. Modelling, studying and implementing the friction force within the quarter-car model was covered by this study; however, in the real world, the effects of friction are so minuscule, as a consequence of variations in the step input. Still, that is vital to preserve the probability of reconsidering friction with a quarter, half and full vehicle models. Also, this study potentially helps in encouraging researchers to implement the sliding contact for spring and viscous damper chassis, which directly influence vehicle stability and road handling. For future work, our underlying motivation is that, when this dynamic behaviour is thoroughly understood, the knowledge can be used to design appropriate feedback controller. Therefore, it might be advisory to install an active actuator, instead of the passive one, to study active system response covering friction effects.

Open Access This article is distributed under the terms of the Creative Commons Attribution 4.0 International License (http:// 
creativecommons.org/licenses/by/4.0/), which permits unrestricted use, distribution, and reproduction in any medium, provided you give appropriate credit to the original author(s) and the source, provide a link to the Creative Commons license, and indicate if changes were made.

\section{Appendix: system equations}

\section{A. Road simulator}

Considering Fig. 1b, the test rig and road simulator schematic diagram, the spool valve displacement $x_{\mathrm{sr}}$ is related to the voltage input $u_{\mathrm{r}}$ by the first-order system as given by:

$\dot{x}_{\mathrm{sr}}=\frac{1}{\tau_{\mathrm{r}}}\left(u_{\mathrm{r}}-x_{\mathrm{sr}}\right)$

where $\tau_{\mathrm{r}}(\mathrm{s})$ is time servovalve constant, $u_{\mathrm{r}}$ is applied voltage, $x_{\mathrm{sr}}(\mathrm{m})$ is the spool servovalve displacement and $\dot{x}_{\text {sr }}(\mathrm{m} / \mathrm{s})$ is spool velocity.

The analysis of hydraulic actuator flow rates equation is displayed in two cases as follows:

Case 1 If $x_{\mathrm{sr}} \geq 0$ when extending, the sign of pressure or pressure differences under square root of the actuator flow rate equation should be checked.

if $P_{\mathrm{sr}}-P_{1 \mathrm{r}} \geq 0$

$Q_{1 \mathrm{r}}=K_{\mathrm{fr}} x_{\mathrm{sr}} \sqrt{P_{\mathrm{sr}}-P_{1 \mathrm{r}}}$

if $P_{\mathrm{sr}}-P_{1 \mathrm{r}}<0$

$Q_{1 \mathrm{r}}=-K_{\mathrm{fr}} x_{\mathrm{sr}} \sqrt{P_{1 \mathrm{r}}-P_{\mathrm{sr}}}$

if $P_{2 \mathrm{r}} \geq 0$

$Q_{2 \mathrm{r}}=K_{\mathrm{fr}} x_{\mathrm{sr}} \sqrt{P}_{2 \mathrm{r}}$

if $P_{2 \mathrm{r}}<0$

$Q_{2 \mathrm{r}}=-K_{\mathrm{fr}} x_{\mathrm{sr}} \sqrt{-P}_{2 \mathrm{r}}$

Case 2 If $x_{\mathrm{sr}}<0$ when retracting,

if $P_{\mathrm{sr}}-P_{2 \mathrm{r}} \geq 0$

$Q_{2 \mathrm{r}}=K_{\mathrm{fr}} x_{\mathrm{sr}} \sqrt{P_{\mathrm{sr}}-P_{2 \mathrm{r}}}$

if $P_{\mathrm{sr}}-P_{2 \mathrm{r}}<0$

$Q_{2 \mathrm{r}}=-K_{\mathrm{fr}} x_{\mathrm{sr}} \sqrt{P_{2 \mathrm{r}}-P_{\mathrm{sr}}}$

if $P_{1 \mathrm{r}} \geq 0$

$Q_{1 \mathrm{r}}=K_{\mathrm{fr}} x_{\mathrm{sr}} \sqrt{P}_{1 \mathrm{r}}$

if $P_{1 \mathrm{r}}<0$

$Q_{1 \mathrm{r}}=-K_{\mathrm{fr}} x_{\mathrm{sr}} \sqrt{-P}_{1 \mathrm{r}}$

The actuator flow rate equations, including compressibility and cross-line leakage effects for both sides, may be written as:

$$
\begin{aligned}
\frac{V_{1 \mathrm{r}}}{\beta_{\mathrm{r}}} \dot{P}_{1 \mathrm{r}} & =Q_{1 \mathrm{r}}-A_{1 \mathrm{r}} \dot{X}_{\mathrm{r}}-\frac{\left(P_{1 \mathrm{r}}-P_{2 \mathrm{r}}\right)}{R_{\mathrm{ir}}} \\
\frac{V_{2 \mathrm{r}}}{\beta_{\mathrm{r}}} \dot{P}_{2 \mathrm{r}} & =A_{2 \mathrm{r}} \dot{X}_{\mathrm{r}}+\frac{\left(P_{1 \mathrm{r}}-P_{2 \mathrm{r}}\right)}{R_{\mathrm{ir}}}-Q_{2 \mathrm{r}} \\
V_{1 \mathrm{r}} & =V_{1 \mathrm{r} 0}+A_{1 \mathrm{r}} X_{\mathrm{r}} \\
V_{2 \mathrm{r}} & =V_{2 \mathrm{r} 0}-A_{2 \mathrm{r}} X_{\mathrm{r}}
\end{aligned}
$$

In addition, Newton's 2nd law for tyre mass is,

$$
\begin{aligned}
\ddot{X}_{\mathrm{r}} M_{\mathrm{r}}= & \left(P_{1 \mathrm{r}} A_{1 \mathrm{r}}-P_{2 \mathrm{r}} A_{2 \mathrm{r}}-B_{\mathrm{vr}} \dot{X}_{\mathrm{r}}-k_{\mathrm{t}}\left(X_{\mathrm{r}}-X_{\mathrm{w}}\right)\right. \\
& -B_{\mathrm{t}}\left(\dot{X}_{r}-\dot{X}_{\mathrm{w}}\right)-M_{\mathrm{T}} g
\end{aligned}
$$

where $M_{\mathrm{r}}$ is tyre mass, the displacements of tyre and wheel are $X_{\mathrm{r}}, X_{\mathrm{W}}$ respectively, the velocity of tyre and wheel are $\dot{X}_{r}, \dot{X}_{\mathrm{W}}$, respectively, $\ddot{X}_{r}$ is the acceleration of tyre mass, $g$ is a ground acceleration.

The suggested PI is:

$u_{\mathrm{r}}=K_{\mathrm{p}} \operatorname{er}(t)+K_{\mathrm{i}} \int_{0}^{\mathrm{t}} \operatorname{er}(t) \mathrm{d} t$

$\operatorname{er}(t)=X_{\mathrm{rdf}}(t)-X_{\mathrm{r}}(t)$

where $u_{\mathrm{r}}$, is applied voltage, $K_{\mathrm{p}}, K_{\mathrm{i}}$ are the proportional and integral gains respectively, er, is the control signal, $X_{\text {rdf }}$ and $X_{\mathrm{r}},(\mathrm{m})$, are the desired filter and measured road displacements respectively.

\section{B. Account of the normal force}

The free body diagram of the test rig is shown in Fig. 4; the friction force acts as an internal force in the tangential direction of the contacting surfaces. Therefore, the inclination position of the suspension units and the type of the system input helped to generate Coulomb friction relatively to this normal force component; this force is accounted as follows:

$$
\begin{aligned}
& F=k_{\mathrm{s}}\left(X_{\mathrm{w}}-X_{\mathrm{b}}\right)+b_{\mathrm{d}}\left(\dot{X}_{w}-\dot{X}_{\mathrm{b}}\right) / \sin (\theta \mp \Delta \theta) \\
& F_{\mathrm{nb}}=F \cos (\theta \mp \Delta \theta) \\
& F_{\mathrm{nb}}=k_{\mathrm{s}}\left(X_{\mathrm{w}}-X_{\mathrm{b}}\right)+b_{\mathrm{d}}\left(\dot{X}_{w}-\dot{X}_{\mathrm{b}}\right) / \tan (\theta \mp \Delta \theta) \\
& F_{\text {fric }}=\mu F_{\mathrm{nb}}
\end{aligned}
$$

where $F_{\text {fric }}$ is the Coulomb frictions, $\mu$ is the friction coefficient, $F_{\mathrm{nb}}$ is the normal force component and $F$ is the spring and damper forces.

While the construction linkage angle is dynamically changed by $\mp \Delta \theta$, from engineering geometry, it can 
be found $\Delta \theta$ as follows:

$$
\begin{aligned}
\frac{L_{\mathrm{d}}-\Delta L_{\mathrm{d}}}{\sin (\theta)} & =\frac{X_{\mathrm{w}}-X_{\mathrm{b}}}{\sin (\Delta \theta)} \\
\sin (\theta) & =\frac{\Delta L_{\mathrm{d}}}{X_{\mathrm{w}}-X_{\mathrm{b}}}
\end{aligned}
$$

$\Delta L_{\mathrm{d}}=\left(X_{\mathrm{w}}-X_{\mathrm{b}}\right) \sin (\theta)$, where, $\Delta L_{\mathrm{d}}$, is the dynamic change in $L_{\mathrm{d}}$, which is the free length of the spring and damper.

Then,

$$
\begin{gathered}
\frac{L_{\mathrm{d}}-\left(X_{\mathrm{w}}-X_{\mathrm{b}}\right) \sin (\theta)}{\sin (\theta)}=\frac{X_{\mathrm{w}}-X_{\mathrm{b}}}{\sin (\Delta \theta)} \rightarrow \\
\sin (\Delta \theta)=\frac{\left(X_{\mathrm{w}}-X_{\mathrm{b}}\right) \sin (\theta)}{L_{\mathrm{d}}-\left(X_{\mathrm{w}}-X_{\mathrm{b}}\right) \sin (\theta)} \\
\sin \Delta \theta=\frac{\left(X_{\mathrm{w}}-X_{\mathrm{b}}\right) \sin (\theta)}{L_{\mathrm{d}}-\left(X_{\mathrm{w}}-X_{\mathrm{b}}\right) \sin (\theta)} \rightarrow \\
\Delta \theta=\sin ^{-1}\left[\frac{\left(X_{\mathrm{w}}-X_{\mathrm{b}}\right) \sin (\theta)}{L_{\mathrm{d}}-\left(X_{\mathrm{w}}-X_{\mathrm{b}}\right) \sin (\theta)}\right]
\end{gathered}
$$

\section{References}

1. Al-Bender, F.: Fundamentals of friction modelling. In: Proceedings of the ASPE Spring Topical Meeting on Control of Precision Systems, MIT, April 11-13, 2010, pp. 117-122 (2010)

2. Awrejcewicz, J., Olejnik, P.: Numerical analysis of selfexcited by chaotic friction oscillations in a two-degrees-offreedom system using the exact Henon method. Mach. Dyn. Probl. 26, 9-20 (2002)

3. Al-Bender, F., Lampaert, V., Swevers, J.: A novel generic model at asperity level for dry friction force dynamics. Tribol. Lett. 16, 81-93 (2004)

4. De Wit, C.C., Olsson, H., Astrom, K.J., Lischinsky, P.: A new model for control of systems with friction. IEEE Trans. Autom. Control 40, 419-425 (1995)

5. Yoon, J.Y., Trumper, D.L.: Friction modelling, identification, and compensation based on friction hysteresis and Dahl resonance. Mechatronics 24, 734-741 (2014)

6. Culbertson, H., Kuchenbecker, K.J.: Importance of matching physical friction, hardness, and texture in creating realistic haptic virtual surfaces. IEEE Trans. Haptics 10, 63-74 (2017)

7. Kudish, I.I.: Revision of a fundamental assumption in the elastohydrodynamic lubrication theory and friction in heavily-loaded line contacts with notable sliding. J. Tribol. 138, 011501 (2016)

8. Pilipchuk, V., Olejnik, P., Awrejcewicz, J.: Transient friction-induced vibrations in a 2-DOF model of brakes. J. Sound Vib. 344, 297-312 (2015)

9. Ibrahim, R.: Friction-induced vibration, chatter, squeal, and chaos-part II: dynamics and modelling. Appl. Mech. Rev 47, 227-253 (1994)

10. Ibrahim, R.: Friction-induced vibration, chatter, squeal, and chaos, Part I: mechanics of contact and friction. Appl. Mech. Rev. 47, 209-226 (1994)
11. Simpson, T., Ibrahim, R.: Nonlinear friction-induced vibration in water-lubricated bearings. Modal Anal. 2, 87-113 (1996)

12. Berger, E.: Friction modelling for dynamic system simulation. Appl. Mech. Rev. 55, 535-577 (2002)

13. Rabinowicz, E.: The nature of the static and kinetic coefficients of friction. J. Appl. Phys. 22, 1373-1379 (1951)

14. Brockley, C., Cameron, R., Potter, A.: Friction-induced vibration. ASME J. Lubr. Technol. 89, 101-108 (1967)

15. Brockley, C., Davis, H.: The time-dependence of static friction. J. Lubr. Technol. 90, 35-41 (1968)

16. Plint, A., Plint, M.: A new technique for the investigation of stick-slip. Tribol. Int. 18, 247-249 (1985)

17. Ibrahim, R., Zielke, S., Popp, K.: Characterization of interfacial forces in metal-to-metal contact under harmonic excitation. J. Sound Vib. 220, 365-377 (1999)

18. Wielitzka, M., Dagen, M., and Ortmaier, T.: State and maximum friction coefficient estimation in vehicle dynamics using UKF. In: American Control Conference (ACC), pp. 4322-4327 (2017)

19. Pathare, Y. S.: Design and development of quarter car suspension test rig model and it's simulation. Int. J. Innov. Res. Dev. ISSN 2278-0211, vol. 3 (2014)

20. Hanafi, D., Fua'ad bin Rahmat, M., bin Ahmad, Z. A., bin Mohd Zaid, A.: Intelligent system identification for an axis of car passive suspension system using real data. In: 6th International Symposium on Mechatronics and its Applications. ISMA’09, pp. 1-7 (2009)

21. Jamei, M., Mahfoul, M., Linkens, D.: Fuzzy based controller of a nonlinear quarter car suspension system. In: Student Seminar in Europe, Manchester, UK (2000)

22. Westwick, D. T., George, K., Verhaegen, M.: Nonlinear identification of automobile vibration dynamics. In: Proceedings of the 7th Mediterranean Conference on Control and Automation, Israel, pp. 724-732 (1999)

23. Buckner, G., Schuetze, K., Beno, J.: Intelligent Estimation of System Parameters for Active Vehicle Suspension Control. CEM Publications, Durham (2015)

24. Hardier, G.: Recurrent RBF networks for suspension system modelling and wear diagnosis of a damper. In: The 1998 IEEE International Joint Conference Neural Networks Proceedings, 1998. IEEE World Congress on Computational Intelligence, pp. 2441-2446 (1998)

25. Alleyne, A., Hedrick, J.K.: Nonlinear adaptive control of active suspensions. IEEE Trans. Control Syst. Technol. 3, 94-101 (1995)

26. Watton, J.: Modelling, Monitoring and Diagnostic Techniques for Fluid Power Systems. Springer, Berlin (2005)

27. Smyth, A.W., Masri, S.F., Kosmatopoulos, E.B., Chassiakos, A.G., Caughey, T.K.: Development of adaptive modeling techniques for non-linear hysteretic systems. Int. J Nonlinear Mech. 37, 1435-1451 (2002)

28. Filipov, A.F.: Differential equations with discontinuous right-hand side. Am. Math. Soc. 93, 191-231 (1988)

29. Surawattanawan, P.: The influence of hydraulic system dynamics on the behaviour of a vehicle active suspension. $\mathrm{PhD}$ thesis, MMM, Cardiff Unversity, Cardiff (2000)

30. Armstrong-Helouvry, B.: Control of Machines with Friction, vol. 128. Springer, Berlin (2012)

31. Armstrong-Hélouvry, B., Dupont, P., De Wit, C.C.: A survey of models, analysis tools and compensation methods for the 
control of machines with friction. Automatica 30, 10831138 (1994)

32. Dupont, P.E.: Avoiding stick-slip through PD control. IEEE Trans. Autom. Control 39, 1094-1097 (1994)

33. Dahl, P.R.: A solid friction model. DTIC Document (1968)

34. Bliman, P., Sorine, M.: Friction modeling by hysteresis operators. Application to Dahl, stiction and Stribeck effects. Pitman Research Notes in Mathematics Series, p. 10 (1993)
35. Ruina, A., Rice, J.: Stability of steady frictional slipping. J. Appl. Mech. 50, 343-349 (1983)

36. Pilipchuk, V.N., Ibrahim, R.A.: Dynamics of a twopendulum model with impact interaction and an elastic support. Nonlinear Dyn. 21, 221-247 (2000) 